\title{
Synthetic 3D PEG-Anisogel Tailored with Fibronectin Fragments Induce Aligned Nerve Extension
}

\author{
Christopher Licht, ${ }^{\dagger}$ Jonas C. Rose, ${ }^{\dagger}$ Abdolrahman Omidinia Anarkoli, ${ }^{\dagger}$ (๑) Delphine Blondel, ${ }^{\S}$ \\ Marta Roccio, ${ }^{\S, \perp}$ Tamás Haraszti, ${ }^{\dagger}$ David B. Gehlen, ${ }^{\dagger}$ Deffrey A. Hubbell, ${ }^{\| \circledast}$ Matthias P. Lutolf, ${ }^{\S}$ \\ and Laura De Laporte*,†, ${ }^{*}$ \\ ${ }^{\dagger}$ DWI - Leibniz Institute for Interactive Materials, 52074 Aachen, Germany \\ ${ }^{\ddagger}$ ITMC - Institute of Technical and Macromolecular Chemistry, RWTH University Aachen, 52074 Aachen, Germany \\ ${ }^{\S}$ Institute for Bioengineering, Ecole Polytechnique Fédérale de Lausanne (EPFL), Lausanne 1015, Switzerland \\ "Pritzker School of Molecular Engineering, University of Chicago, Chicago, Illinois 60637, United States \\ ${ }^{\perp}$ Department of Biomedical Research, University of Bern, 3010 Bern, Switzerland
}

\section{Supporting Information}

ABSTRACT: An enzymatically cross-linked polyethylene glycol (PEG)-based hydrogel was engineered to promote and align nerve cells in a three-dimensional manner. To render the injectable, otherwise bioinert, PEG-based material supportive for cell growth, its mechanical and biochemical properties were optimized. A recombinant fibronectin fragment (FNIII9*-10/ 12-14) was coupled to the PEG backbone during gelation to provide cell adhesive and growth factor binding domains in close vicinity. Compared to full-length fibronectin, FNIII9*-10/1214 supports nerve growth at similar concentrations. In a 3D environment, only the ultrasoft 1 $\mathrm{w} / \mathrm{v} \%$ PEG hydrogels with a storage modulus of $\sim 10 \mathrm{~Pa}$ promoted neuronal growth. This gel was used to establish the first fully synthetic, injectable Anisogel by the addition of magnetically aligned microelements, such as rod-shaped microgels or short fibers. The Anisogel led to linear neurite extension and represents a large step in the direction of clinical translation with the opportunity to treat acute spinal cord injuries.

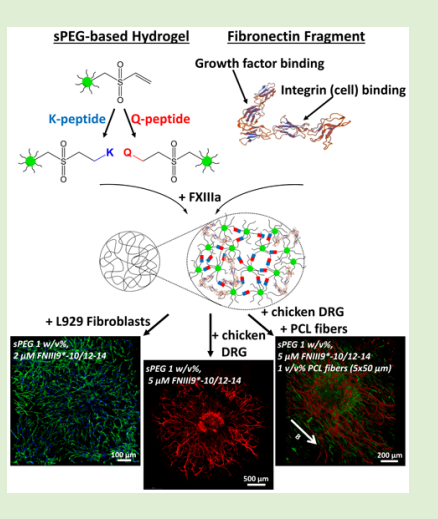

\section{INTRODUCTION}

Hydrogels have been widely used as biomaterials for 3D tissue regeneration. ${ }^{1-3}$ They are formed by cross-linking natural and/ or synthetic glycosaminoglycans, proteins, and/or polymers and can take up water up to 400 times of their dry weight. ${ }^{4}$ In the case of synthetic polymers, the network can be established via different cross-linking chemistries, inducing physical or covalent bonds. To grow tissues inside these 3D synthetic matrices, hydrogels are often modified with biological domains to mimic different molecules of the extracellular matrix (ECM), depending on the application. ${ }^{5}$ These biochemical functionalities can contain cell adhesive or signaling domains, degradable sequences, and growth factor- or cytokineinteracting molecules. ${ }^{6-9}$ Synthetic polymeric hydrogels have the advantage that their mechanical and physical properties can be fine-tuned by altering the concentration, structure, and molecular weight of the polymers used to form the backbone of the hydrogels. ${ }^{10,11}$ Cell behavior has been demonstrated to be strongly affected by the stiffness, viscoelasticity, mesh size, and degradation rate of the hydrogel, in addition to the cell type, and whether the cells are grown in $2 \mathrm{D}$ on top of a hydrogel or in $3 \mathrm{D}$ inside a hydrogel. ${ }^{12-15}$ For example, on a 2D elastic hydrogel, most cells grow better on stiff substrates, ${ }^{16-18}$ while in a $3 \mathrm{D}$ hydrogel, their migration and proliferation is optimal in softer hydrogels $\left(G^{\prime} \sim 100 \mathrm{~Pa}\right) .{ }^{19,20}$
Providing a soft, open network is even more critical in the case of sensitive nerve cells, as this better replicates the mechanical properties of native nerve tissue. ${ }^{21-27}$ In addition, in contrast to fast proliferating cells, lower levels of MMPs may be produced to degrade the hydrogel network, requiring a more open structure from the onset.

One of the most common synthetic polymers employed to produce tissue regenerative constructs is poly(ethylene glycol) (PEG), as it is biocompatible and approved for clinical use. $^{28-30}$ To obtain homogeneous PEG hydrogels, star-PEG molecules (sPEG) have been end-modified with functional groups that can cross-link via a step-growth mechanism., ${ }^{5,31-33}$ The advantage of star-shaped polymers is that not all arms have to react to form a network, leaving multiple arms for further modifications. In addition, the degradation products have a smaller radius of gyration compared to linear polymers, enabling easier clearance by the kidneys. ${ }^{34}$ To achieve mild enzymatic gelation under physiological conditions and a versatile method to add biofunctional domains during crosslinking, sPEG-vinylsulfone (sPEG-VS) has been modified with complementary peptide sequences to mimic the trans-

Received: June 26, 2019

Revised: September 22, 2019

Published: October 15, 2019 
glutaminase-induced cross-linking mechanism of fibrin. ${ }^{35}$ As most synthetic hydrogels are cross-linked via covalent bonds and contain nanometer-scale mesh sizes, they have to degrade over time to enable cell migration and proliferation. This can be achieved via ester bonds to allow hydrolysis ${ }^{20,36}$ or specific matrix metalloprotease (MMP)-sensitive peptide domains, which induce on cell demand degradation. ${ }^{37-39}$

To support nerve growth inside hydrogels, biofunctional proteins, such as fibronectin, ${ }^{13,23}$ laminin, ${ }^{40,41}$ or Matrigel, ${ }^{42,43}$ and combinations of shorter peptides ${ }^{6,44,45}$ have been mixed or covalently linked to tailor a multitude of hydrogels. In the synthetic fibrin-mimetic, PEG-based hydrogel, one of the peptide sequences contains an MMP sensitive domain for degradation, while peptides ${ }^{35}$ and ECM fragments ${ }^{8,46}$ can be engineered and produced, bearing the transglutaminase substrate, to covalently link into the matrix. Synthetically produced proteins have the advantage of avoiding cross-species reactions or potential pathogen transmission, which are possible risks when biofunctionalizing a material using native proteins (e.g., fibronectin) obtained from either animal or human sources. The fibronectin fragment FN9*-10/12-14 is an example of an engineered ECM fragment, which contains multiple integrin-binding domains for cell adhesion (FN9*-10) and a heparin-binding domain (FN12-14) that interacts with a wide library of growth factors and cytokines, including brainderived neurotrophic factor (BDNF) and neurotrophin 3 (NT3). ${ }^{47}$ By substituting Leu 1408 with Pro (FN9 $\rightarrow$ FN9*), the conformational stability of the FN9 module is increased 2-3fold, resulting in enhanced biological activity. ${ }^{48}$ Fibrin hydrogels modified with this fragment have been demonstrated to promote wound healing in diabetic mice in the presence of vascular growth factor (VEGF-A165) and platelet-derived growth factor (PDGF-BB), and bone formation in rats in the presence of bone morphogenic protein (BMP-2) and PDGF$\mathrm{BB}^{46}$

In the case of sensitive nervous tissue, such as the spinal cord, minimally invasive therapies for tissue repair are required. ${ }^{49}$ Therefore, injectable PEG solutions or hydrogel precursors have been applied in an attempt to regenerate the spinal cord after injury, while avoiding further damage caused by additional surgery. ${ }^{22,50-54}$ One remaining limitation, however, is the isotropic architecture of the formed hydrogel networks after injection, which does not provide unidirectional guidance for the regenerating nerves in this highly oriented tissue. Therefore, magnetic particles have been mixed inside hydrogel precursors to form strings in the presence of a magnetic field and provide anisotropic structures for cell guidance. ${ }^{55,56}$ To significantly reduce the amount of iron oxide and provide more control over the dimensions and properties of the guiding elements, we recently developed a novel injectable hybrid hydrogel system that has been reported as the material Anisogel. It contains magneto-responsive, rod-shaped microgels ${ }^{57,58}$ or short fibers, ${ }^{59}$ and a surrounding fibrin precursor solution. After injection, the microgels or fibers align in a low external magnetic field in the milli Tesla range, during which the fibrin gel is cross-linked to fix the anisotropy of the material after removal of the magnetic field. These types of Anisogels have been demonstrated to induce linear growth of functional nerves with a minimal amount of guidance required but used fibrin as the surrounding gel, which is known to degrade too rapidly in vivo. ${ }^{60}$

In this report, we demonstrate the functionality of the first fully synthetic PEG-based Anisogel for oriented cell and nerve growth, which provides complete control over the properties and facilitates clinical translation. The surrounding synthetic hydrogel backbone cross-links and degrades enzymatically and is modified with the fibronectin fragment FN9*-10/12-14. First, a synergistic effect of this fragment to stimulate neurite extensions is demonstrated. Then, the mechanical and biochemical properties of the master hydrogel are fine-tuned to achieve optimal 3D fibroblast and nerve growth. Finally, magneto-responsive, nonadhesive rod-shaped microgels or short, cell-adhesive fibers are incorporated and aligned inside the hydrogel in the presence of a magnetic field to form the Anisogels. Both types of Anisogels are compared in their ability to induce linear nerve growth along the anisotropic axis of the gel.

\section{EXPERIMENTAL SECTION}

2.1. Synthesis of Star-PEG Precursor. Star PEG-conjugates are prepared via Michael-type addition as described elsewhere. ${ }^{35}$ Briefly, either NQEQVSPLERCG-NH $\mathrm{H}_{2}$ or Ac-FKGGGPQG $\downarrow$ IWGQERCG$\mathrm{NH}_{2}$ are added to an eight-arm sPEG-VS in a 1.2-fold molar excess over the VS groups and dissolved in $0.3 \mathrm{M}$ triethanolamine $\left(\mathrm{N}(\mathrm{EtOH})_{3}, \mathrm{pH} 8.0\right)$, resulting in SPEG-Q and sPEG-K, respectively. The K-peptide contains a matrix metalloproteinase (MMP) sensitive domain GPQG $\downarrow I W G Q$, which can be cleaved by the MMPs produced by the cells. The reaction takes place at $37{ }^{\circ} \mathrm{C}$ for $2 \mathrm{~h}$. The products are subsequently dialyzed against double distilled water $\left(\mathrm{ddH}_{2} \mathrm{O}\right)$ for at least 4 days at $4{ }^{\circ} \mathrm{C}$ using Slide-A-Lyzer dialysis cassettes (ThermoFisher, MWCO 3.5K). After dialysis and lyophilization, both products (PEG-Q and PEG-K) are obtained as a white powder. Successful binding of each peptide to the sPEG-VS backbone is confirmed via ${ }^{1} \mathrm{H}$ NMR spectroscopy (Figure S1).

2.2. Hydrogel Formation. A PEG-based hydrogel is formed via enzymatic cross-linking between PEG-Q and PEG-K at a molar ratio of 1:1. The enzyme, Factor XIII (CSL Behring GmbH, 1250 U FXIII) is activated by diluting $200 \mathrm{U} / \mathrm{mL}$ thrombin in an optimized buffer $\left(25 \mathrm{mM} \mathrm{CaCl}_{2}, 10 \mathrm{mM}\right.$ TRIS, $150 \mathrm{mM} \mathrm{NaCl}$ ) at a volume ratio of 1:9 and letting it react for $30 \mathrm{~min}$ at $37{ }^{\circ} \mathrm{C}$ while vortexing gently every $5 \mathrm{~min}$. The sPEG solution is buffered using a $10 \times$ buffer $(0.1 \mathrm{M}$ $\mathrm{CaCl}_{2}, 0.5 \mathrm{M}$ Tris, $1.1 \mathrm{M} \mathrm{NaCl}$ ) and $10 \mathrm{U} / \mathrm{mL}$ FXIIIa is added for cross-linking. The gelation rate can be fine-tuned by varying the FXIIIa concentration. The spare volume can be used to add cells, celladhesive peptides or proteins, or $\mu$-elements. If not stated, $\mathrm{ddH}_{2} \mathrm{O}$ is added. After $5 \mathrm{~min}$ at room temperature, the gelation is continued for $20 \mathrm{~min}$ at $37^{\circ} \mathrm{C}$ in the incubator.

2.3. Production of Fibronectin Fragments. The fibronectin fragments are produced in BL21 Gold (DE3) E. coli and purified by Glutathione $S$-transferase (GST) affinity, in a method adapted from previous reports. ${ }^{8}$ BL21 Gold (DE3) E. coli are cultured in $3 \mathrm{~mL}$ 2XYT media ( $16 \mathrm{~g}$ Tryptone, $10 \mathrm{~g}$ yeast extract, $5 \mathrm{~g} \mathrm{NaCl}$ ) overnight at $37^{\circ} \mathrm{C}$. One milliliter of the culture is used to inoculate another 200 $\mathrm{mL}$ medium and the expression is initiated at an optical density of $0.6-0.8$ by the addition of $1 \mathrm{mM}$ Isopropyl $\beta$-D-thiogalactopyranosid (IPDI). After overnight expression at $20{ }^{\circ} \mathrm{C}$, the culture is spun down and cell pellets are lysed using $100 \mathrm{~mL}$ lysis buffer (100 mg lysozyme and $100 \mu \mathrm{L}$ phenyl methyl sulfonyl fluoride in PBS) for resuspension and ultrasonication $(65 \%, 4 \times 15 \mathrm{~s} / 15 \mathrm{~s}$ on/off cycles). Afterwards, $\mathrm{MgCl}_{2}$ is added to a final concentration of $20 \mathrm{mM}$, Triton-X 100 to $1 \%$, and $6 \mu \mathrm{L} / \mathrm{mL}$ DNase and RNase, after which the lysates are shaken at $4{ }^{\circ} \mathrm{C}$ for $30 \mathrm{~min}$. Lysates are then spun down, aliquoted, and stored at $-20{ }^{\circ} \mathrm{C}$ until purification. FNIIII*-10/12-14 purification is carried out with an Äkta Prime (GE Healthcare Life Sciences) via GST affinity chromatography. The GST-tag is cleaved from the protein by $4 \mathrm{U} / \mathrm{mL}$ PreScission protease (GE Healthcare Life Sciences) during dialysis (Slide A Lyzer, MWCO 3.5K) in $10 \mathrm{mM}$ Imidazole (AppliChem) at $4{ }^{\circ} \mathrm{C}$. After $24 \mathrm{~h}$, the GST-tag is separated from the pure protein by a second GST affinity chromatography step. The cleaved products and the final purified protein are detected by means of sodium dodecyl sulfate polyacrylamide gel electrophoresis 
(SDS-Page) with a PageRuler Prestained Protein Ladder 13 (Thermo Fisher) (Figure S5). The pure protein is sterile filtered $(0.22 \mu \mathrm{M})$, aliquoted, and stored at $-80^{\circ} \mathrm{C}$.

2.4. Robotic Spotter. A robotic spotter technique using a Q-array mini robotic spotter (Genetix) is utilized to analyze the fibronectin fragments for neurite extension. Per experiment, four hydrogel substrates are tested, each one containing the same cell suspension but different media. Each gel $(25 \times 75 \mathrm{~mm})$ consists of 7 fields, with each field containing 288 spots with 36 spots per fragment. Therefore, 8 proteins can be tested in parallel on 1 hydrogel substrate, but here, 7 different protein solutions are investigated. The positions of the fragments are scrambled for each field to allow for randomization. The method is adapted from a previous report to enable enzymatically induced binding of the fragments. ${ }^{67}$ Briefly, a $384 \mu \mathrm{L}$ plate is filled with $100 \mu \mathrm{L}$ of the spotting solutions, containing $13 \mu \mathrm{L}$ enzymatic cross-linking solution (18.75 U/mL FXIIIa) and $30 \mu \mathrm{L}$ glycerol. Therefore, $57 \mu \mathrm{L}$ volume is left for the different fibronectin fragments and full-length fibronectin. As the stock concentration of full-length fibronectin $(220 \mathrm{kDa})$ solution was $1 \mu \mathrm{g} / \mu \mathrm{L}$, only a final concentration of $0.2 \mathrm{nM}$ is added, whereas the smaller fragments, ranging from 21 to $51 \mathrm{kDa}$, are added at a final concentration of $1 \mathrm{nM}$. A microfabricated stamp, containing micropillar features, then dips into the solutions to sequentially deposit the proteins on a twodimensional PEG hydrogel, cross-linked via Michael-type addition and modified with the lysine containing peptide (Ac-FKGGERCG$\mathrm{NH}_{2}$ ). All fragments and full-length fibronectin contain the transglutaminase substrate NQEQVSPL to enable covalent binding of the fragments with the free amines present in the gel via FXIIIa. The stamps are pressed onto the hydrogel substrate for $2 \mathrm{~h}$ to create fragment-containing spots with a diameter of $450 \mu \mathrm{m}$. Subsequent washing with PBS ( $\mathrm{pH}$ 7.4) and UV light sterilization are performed to prepare the arrays for cell experiments. To visualize the binding efficiency of the fragments to the spot, FN9-10 is pre-coupled to Rhodamine.

2.5. Production of Anisometric Microgels. Rod-shaped microgels $(\mu$-gels $)$ are produced with a mold-based soft lithography approach as previously described. ${ }^{57}$ Briefly, $3 \mathrm{kDa}$ six-armed starshaped poly(ethylene oxide-stat-propylene oxide) with acrylate end groups (sPEG-A) are cast into a highly repelling perfluoropolyether (PFPE) mold in the presence of a photoinitiator and fluorescein $o$ acrylate. After $1 \mathrm{~h} \mathrm{UV}$-curing of the solution-filled features, fluorescent microgels with precise mold replication are received. To avoid incomplete filling of the molds due to water evaporation, sPEG-A is blended with another nonvolatile, nonreactive 200 Da linear PEG. The individual microgel objects are removed from the mold by putting them in contact with a sticky polyvinylpyrrolidone layer that can be dissolved in water afterward. The nonreactive PEG filler is easily washed out in water, and after several washing steps in water, microgels of a typical size of $50 \times 5 \times 5 \mu \mathrm{m}^{3}$ are obtained at a sPEG-A concentration of $20 \mathrm{w} / \mathrm{v} \%$.

2.6. Production of Short Fibers. Short fibers are produced based on previously published reports. ${ }^{59,61}$ Briefly, polymer solution is prepared by dissolving polycaprolactone (PCL) with an average molecular weight of $80 \mathrm{kDa}$ (Sigma-Aldrich, Germany) in 50:50 v/v chloroform:acetic acid (Sigma-Aldrich, Germany) at a concentration of $17 \mathrm{w} / \mathrm{v} \%$. A precise amount of synthesized SPIONs (1 wt \% of polymer weight) is dispersed into the polymer solution using $10 \mathrm{~min}$ of ultrasonication (Sonifier W-250D Brandson) prior to the spinning process.

Uniform aligned fibers with $\sim 5 \mu \mathrm{m}$ diameter are collected using the solvent assisted spinning (SAS) technique. In SAS, syringes $(1 \mathrm{~mL})$ are filled with the prepared solution and the feed rate $(Q=60 \mu \mathrm{L} / \mathrm{h})$ is controlled by a programmable syringe pump (Aladdin, WPI). As the solution is pushed through the needle (21G), it forms a hemispherical shape at the tip, which is manually drawn toward the rotating cylindrical drum (radius $=2.5 \mathrm{~cm}$ ) that is located at $10 \mathrm{~cm}$ vertical distance under the needle. Aligned microfibers are harvested from the drum and placed in a custom-designed polyethylene cryomold. Optimal cutting temperature (OCT) gel (Sakura Finetec) is added and the aligned fibers are frozen inside the mold using dry ice. The resulting block of solidified gel with the aligned fiber stack embedded therein is sectioned perpendicular to the direction of fibers, using a cryostat microtome (Leica CM3000 Cryosat) maintained at $-20^{\circ} \mathrm{C}$. Magneto responsive short fibers are obtained by dissolution of the OCT gel and repeating washing steps with distilled water.

2.7. Preparation of Anisogel. A fully synthetic Anisogel is prepared either with $\mu$-gels or with short fibers. In general, the $\mu$ elements are dispersed in cell medium replacing part of the spare volume to produce the hydrogel. Two stock solutions are prepared: stock A consists of buffer, the sPEG-mix, and potential peptides or proteins, whereas stock $\mathrm{B}$ contains the $\mu$-element solution and FXIIIa. Stock $\mathrm{B}$ is divided into aliquot portions of the required amount for one gel, and the corresponding amount of stock $\mathrm{A}$ is added and subsequently pipetted in between magnets, generating a magnetic field of $\sim 100 \mathrm{mT}$. After 20 min gelation time, medium is added. In the case of $\mu$-gels, the FXIIIa concentration is increased to $20 \mathrm{U} / \mathrm{mL}$ to prevent sedimentation of the elements. Due to the higher weight of the fibers, consisting of $100 \%$ polymer, a concentration of $100 \mathrm{U} / \mathrm{mL}$ FXIIIa is used to ensure a homogeneous distribution of fibers throughout the gel. In both cases, the $\mu$-elements are added to obtain a final concentration of $1 \mathrm{v} / \mathrm{v} \%$.

2.8. Analysis of Neurite Outgrowth. To analyze neurite extension on the $2 \mathrm{D}$ hydrogels prepared with the robotic spotter, 12 random spots (out of 36) per field, per protein, and per media condition are selected for quantification with Neuron $J$ using a random number generator. The entire neurite length is traced per spot. Therefore, for each combination of protein and medium, the neurite growth of 84 spots is added and normalized to the sum of neurite length for all conditions ( 84 spots $\times 7$ protein conditions $\times 4$ media conditions). The experiment was performed twice and the standard deviation is calculated for both experiments.

To quantify neurite outgrowth from DRGs inside the 3D hydrogels, the region of the explant of the DRG is cut out. The images are rendered binary by using a threshold via the Otsu method and analyzed by a self-developed MatLab method, which determines the amount of nonzero valid image pixels at a specific distance (radius) from the edge of the explant. The density of pixels is determined by dividing the number of the pixels by the circumference in which they are counted. The distance at which the level drops to half of the maximum density is defined as "neurite outgrowth".

The alignment of the $\mu$-elements and neurite extensions are quantified using an orientation analysis on the images using an elliptical Mexican hat filter (a Laplace operator applied on an elliptic two-dimensional Gaussian function). ${ }^{62,63}$ The images are first background-corrected using a rolling ball filter when required. DRG images are smoothed with a Gaussian filter. The size of the filters is tuned to the actual data stack, which is a rolling ball radius of $8-16$ pixels and a smoothening Gaussian standard deviation of $0.75-1.0$ pixels. For images with features broader than a few pixels, an edge detector is applied based on the absolute magnitude of the gradient using the first derivative of the smoothening Gaussian function. The Mexican hat kernel (standard deviation is typically 1.0 and 20.0 pixels in the $X$ - and $Y$-directions, respectively) is applied at various orientations in 20 steps in the $\left[-90^{\circ}, 90^{\circ}\right]$ half-opened interval. The kernels are convolved to the filtered images, and the orientation with maximal intensity is selected for each pixel. The maximum intensity data is filtered using a threshold generated by Otsu's method. Pixels below this threshold are deleted. The angle data of the remaining pixels are summarized in a histogram. For comparison, this histogram is rotated, setting its maximum as the zero angle. The full width at half-maximum (FWHM) is determined using linear interpolation between the data points.

2.9. Statistics. Statistical analysis is performed in Origin 2016 for Windows. A one-way ANOVA is applied with $p$-values below 0.05 being considered significant and a correction of the $p$-value for multiple hypotheses according to the Bonferroni correction. 


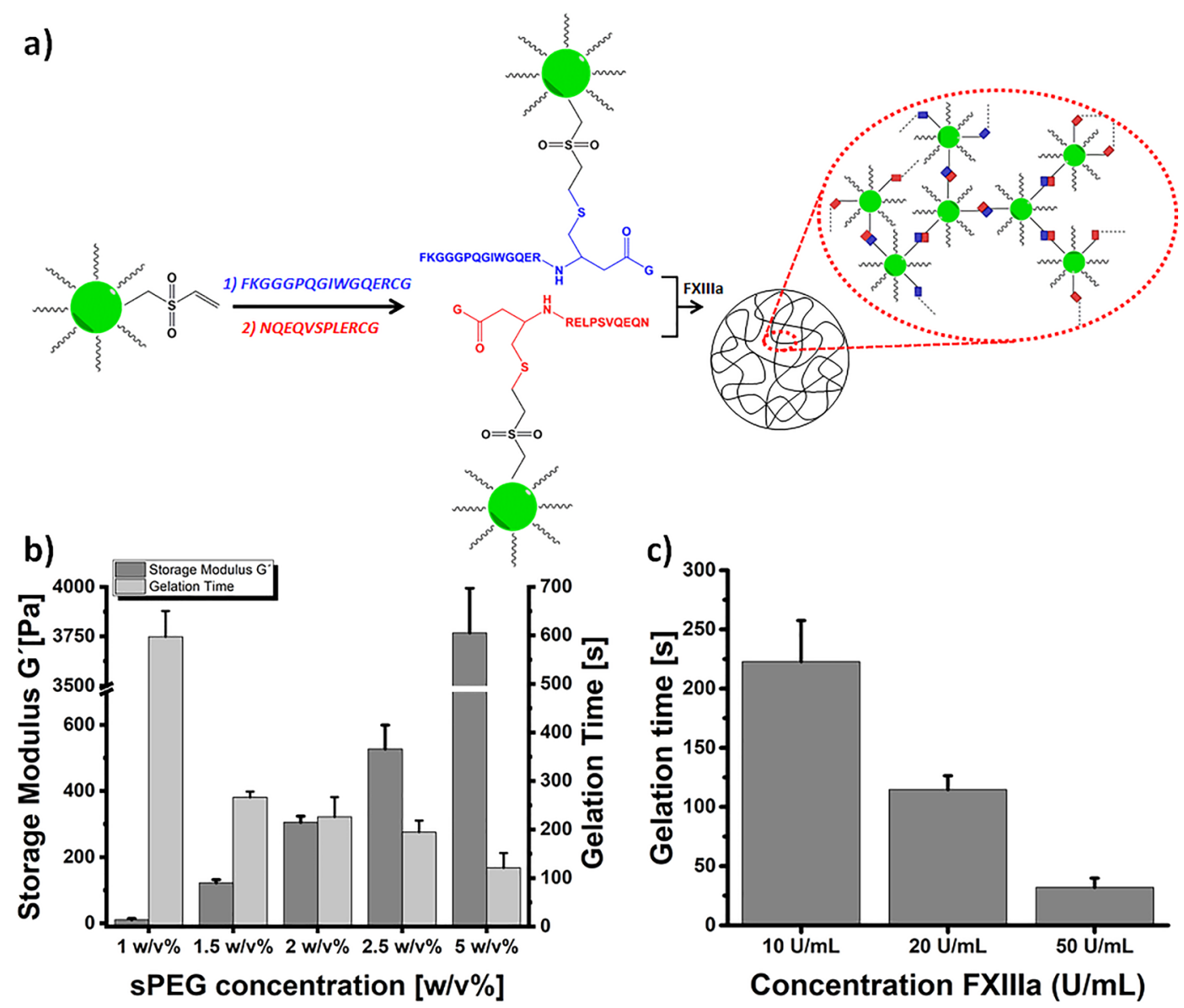

Figure 1. (a) Schematic of peptide binding to sPEG-VS and the following cross-linking via FXIIIa to form a hydrogel. (b) Resulting mechanical properties and gelation times of hydrogels containing different sPEG concentrations. (c) Effect of the FXIIIa concentration on the gelation time.

\section{RESULTS AND DISCUSSION}

3.1. Conjugate Synthesis and Hydrogel Formation. Synthetic PEG-based hydrogels, prepared via enzymatic crosslinking, are used as described before. ${ }^{35}$ Two batches of eightarm star-PEG-vinylsulfone (sPEG-VS) were functionalized via a biocompatible Michael-type addition using two different cysteine-containing peptides, which can be performed at physiological $\mathrm{pH}$. One peptide consists of a transglutaminase substrate providing glutamine (H-NQEQVSPLERCG- $\mathrm{NH}_{2}=$ $\mathrm{Q}$, which forms a $\gamma$-glutamythiolester with FXIIIa. The other peptide has a lysine to deliver a free amine as counterpart (AcFKGGGPQGIWGQERCG- $\left.\mathrm{NH}_{2}=\mathrm{K}\right) .{ }^{64}$ Besides lysine, the $\mathrm{K}$ peptide contains an MMP degradable sequence (GPQG $\downarrow$ IWGQ) to foster on cellular demand degradation, so that the gel remains as long as required to support nerve growth. The peptide modification of the sPEG-VS was confirmed by ${ }^{1} \mathrm{H}$ NMR with full conversion of the VS-groups (Figure S1). In the presence of activated transglutaminase Factor XIII (FXIIIa), an isopeptide bond is formed between the amino acids $\mathrm{Q}$ and $\mathrm{K}$, mimicking the cross-linking mechanism of fibrin (Figure 1a). Mixing both sPEGs conjugated with the peptides in a $1: 1$ molar ratio at a concentration of $1 \mathrm{w} / \mathrm{v} \%$ and a minimum concentration of $10 \mathrm{U} / \mathrm{mL}$ FXIIIa resulted in the formation of a hydrogel within $10 \mathrm{~min}$.

3.2. Mechanical and Structural Properties of the Hydrogels. Both the gelation rate and mechanical properties were analyzed for sPEG concentrations, ranging from 1 to $5 \mathrm{w} /$ $\mathrm{v} \%$ in the presence of $10 \mathrm{U} / \mathrm{mL}$ FXIIIa. To mimic the natural
ECM surrounding nerve cells, a stiffness of $0.1-1 \mathrm{kPa}$ is desirable. ${ }^{52,65}$ Depending on the sPEG concentration, the storage modulus of the hydrogels ranged from $10 \mathrm{~Pa}(1 \mathrm{w} / \mathrm{v} \%)$ to $3800 \mathrm{~Pa}(5 \mathrm{w} / \mathrm{v} \%)$ (Figure $1 \mathrm{~b})$, with its highest increase in stiffness between 2.5 and $5 \mathrm{w} / \mathrm{v} \%$ ( $\sim 7$-fold). These results are in accordance with previously reported observations. ${ }^{19}$ Importantly, the use of injectable materials in preclinical and clinical settings requires sufficient stability, and thus rapid cross-linking, to avoid leakage from an injury site. However, enough time is needed to allow for proper injection and orientation of the magneto-responsive, anisometric elements $(\sim 1 \mathrm{~min})$ in the case of the Anisogel. After orientation, the hydrogel fixes the aligned micron-scale elements. Therefore, the range of gelation rates of this PEG system was investigated by determining the gelation point as the first value at which the $\tan (\delta)$ (defined as the loss modulus $\left(G^{\prime \prime}\right)$ divided by the storage modulus $\left(G^{\prime}\right)$ ) drops below 0.1 (Figure S2a). The extremely soft gels $\left(G^{\prime} \sim 10 \mathrm{~Pa}\right)$ were formed with a gelation time of approximately $10 \mathrm{~min}$, while increasing the sPEG concentration to $1.5 \mathrm{w} / \mathrm{v} \%$ doubled the gelation rate and $5 \mathrm{w} / \mathrm{v}$ $\%$ sPEG further reduced the gelation time to approximately 2 $\mathrm{min}$. Furthermore, the effect of different FXIIIa concentrations $(10-50 \mathrm{U} / \mathrm{mL})$ on the gelation rate and stiffness of the gels was tested at a fixed amount of sPEG ( $2 \mathrm{w} / \mathrm{v} \%)$ (Figure 1c). In the case of $10 \mathrm{U} / \mathrm{mL}$ FXIIIa, the gelation point occurred after approximately $4 \mathrm{~min}$, while doubling the amount of FXIIIa reduced this time by a factor 2 . In the case of $50 \mathrm{U} / \mathrm{mL}$ FXIIIa, gelation took place in less than $1 \mathrm{~min}$. Despite the effect on the 
a)

c)

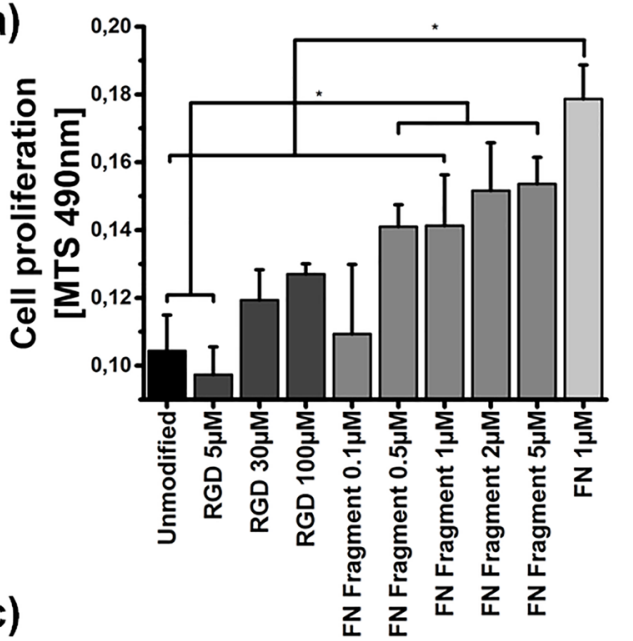

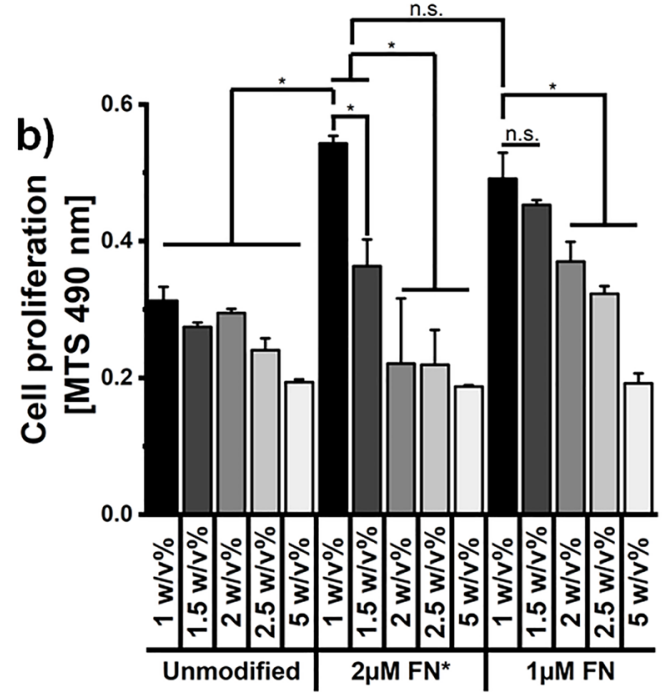

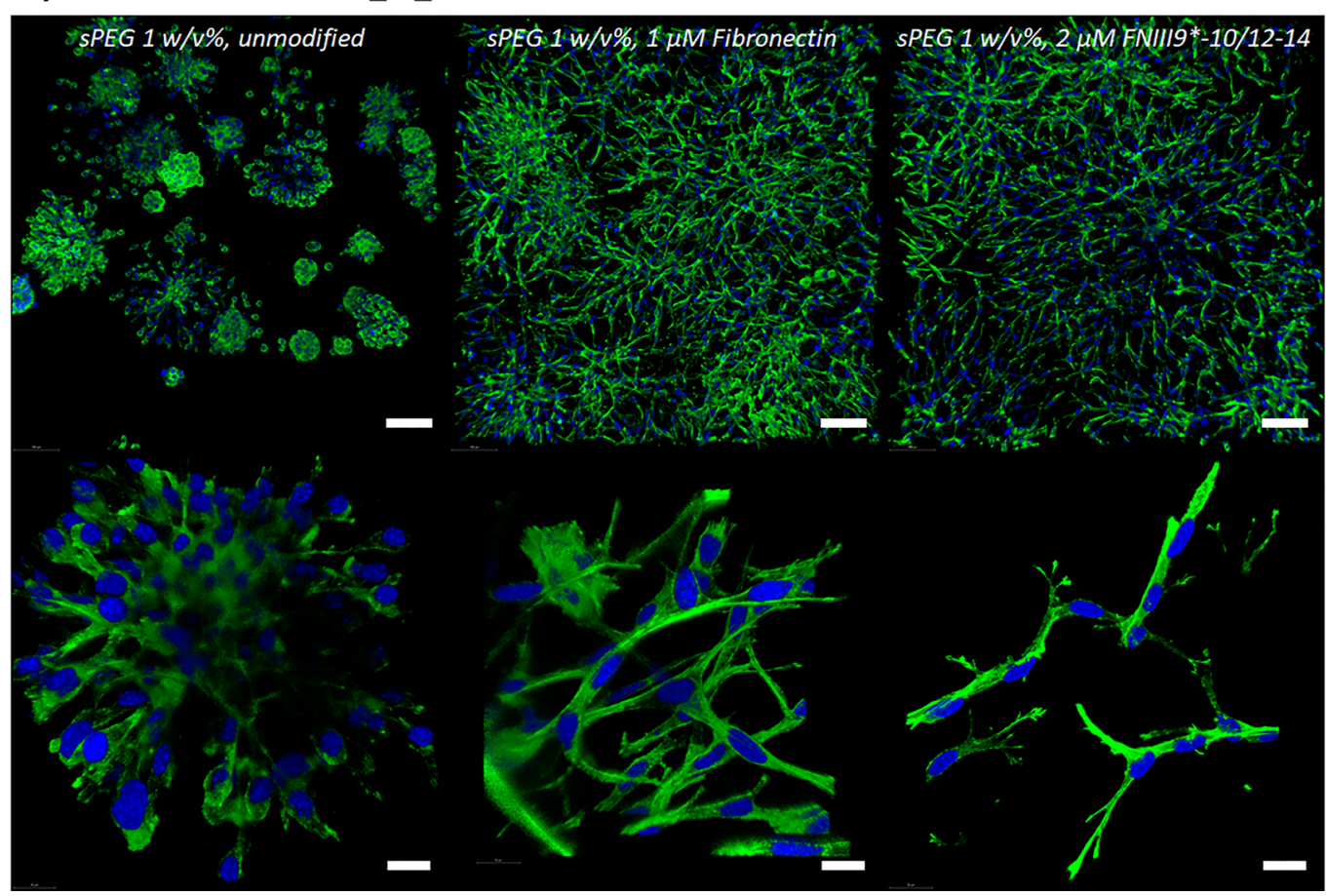

Figure 2. (a) Cell proliferation after 7 days for different concentrations of RGD, FNIII9*-10/12-14, and full-length fibronectin in a 2 w/v\% sPEG gel. (b) Cell proliferation after 7 days in unmodified gels, gels modified with $2 \mu \mathrm{M}$ FNIII9*-10/12-14, or $1 \mu \mathrm{M}$ full-length fibronectin gels for hydrogels with a stiffness ranging from 10 to $3500 \mathrm{~Pa}$. (c) Morphological differences of fibroblasts mixed and grown inside a $1 \mathrm{w} / \mathrm{v} \%$ synthetic sPEG hydrogels, unmodified or modified with $2 \mu \mathrm{M}$ FNIII9*-10/12-14 or $1 \mu \mathrm{M}$ fibronectin. Data presented as average \pm s.d. and statistical significance performed using two-way/one-way ANOVA with Bonferroni comparison $\left({ }^{*} p<0.05\right)$. Scale bars are $100 \mu \mathrm{m}$ (top images) and $20 \mu \mathrm{m}$ (bottom images).

gelation time, the enzyme concentration did not significantly change the final stiffness of the gels (Figure S2b). When replacing water with media, the gels required an additional $\sim 30 \mathrm{~s}$ to cross-link, but the stiffness remained unchanged (Figure S2c). The incorporation of different biomolecules into the hydrogel at their relevant concentrations also did not change the mechanical behavior of the hydrogels (Figure S2d). Therefore, results obtained from samples containing different biological domains can be attributed exclusively to the bioactivity of the protein.

The internal structure of the hydrogel affects diffusion of nutrients and growth factors, while it can also influence how fast the cells can degrade the structure to enable cell migration. To estimate the internal structure of the hydrogels, the critical concentration $\left(c_{\mathrm{c}}\right)$ was calculated. When the concentration drops below the critical concentration $\left(c_{c}\right)$, not all sPEG molecules touch each other, which would lead to a heterogeneous network. ${ }^{66}$ To determine the $c_{\mathcal{C}}$ initially, two approaches were performed. In the first one, the hydrodynamic radius $\left(r_{\mathrm{H}}\right)$ of the $\mathrm{sPEG-Q}$ was estimated to be $3.1 \mathrm{~nm}$ via dynamic light scattering (DLS) (Figure S3a). Based on this value, $c_{\mathrm{c}}$ was calculated to be $21.5 \mathrm{w} / \mathrm{v} \%$ according to eq 1 with a total volume $\left(V_{\mathrm{T}}\right)$ of $50 \mu \mathrm{L}$, the Avogadro constant $N_{\mathrm{A}}$, and the width (a) of the sPEG-Q molecule $\left(M_{\mathrm{w}}: 30684 \mathrm{~g} / \mathrm{mol}\right.$, 

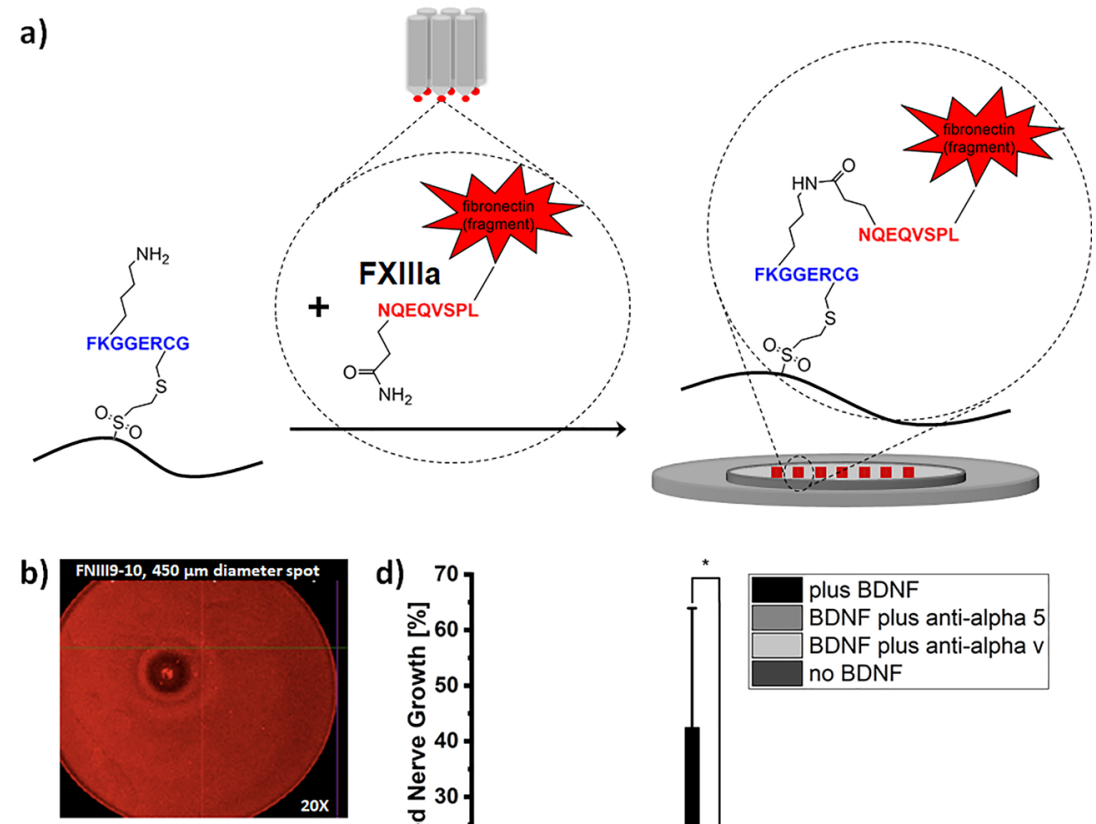

c)
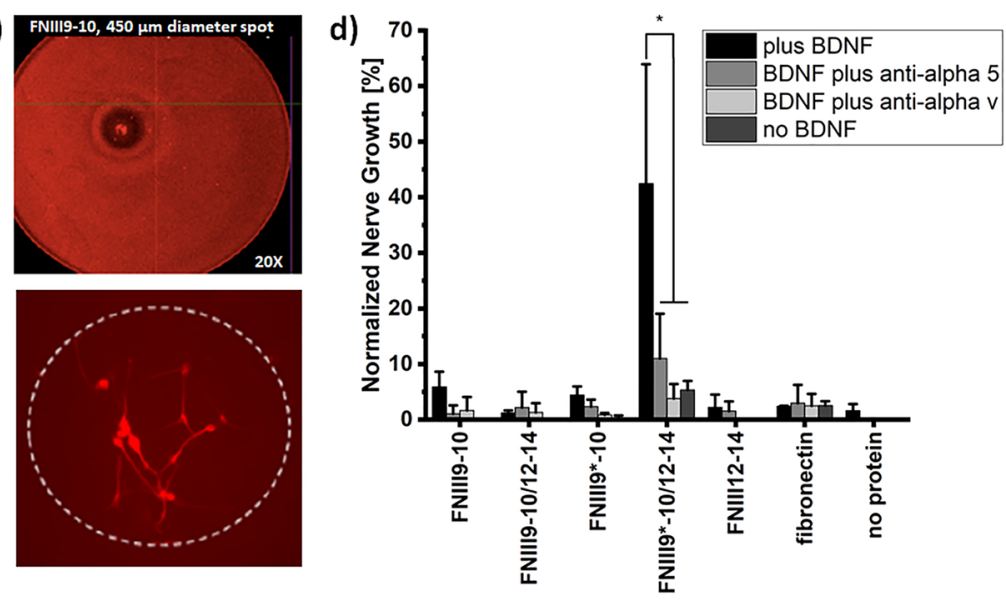

Figure 3. (a) Schematic of binding the fibronectin fragments to the spots on a $2 \mathrm{D}$ sPEG gel. (b) Fluorescently labeled FN9-10 fragment coupled to a spot in a homogeneous manner. (c) TuJ1 staining of 2D nerve growth inside an exemplary spot. (d) Normalized nerve growth to the total growth on all gels for different fibronectin fragments, full-length fibronectin, and unmodified surfaces and different media conditions.

diameter $\sim 6.2 \mathrm{~nm})$, assuming a similar size for sPEG-K $\left(M_{\mathrm{w}}\right.$ : $33736 \mathrm{~g} / \mathrm{mol})$.

$$
a=\sqrt[3]{\frac{V_{\mathrm{T}}}{n \times N_{\mathrm{A}}}} \Rightarrow c_{\mathrm{c}}=\frac{M_{\mathrm{w}}}{a^{3} N_{\mathrm{A}}}
$$

In a second approach, $c_{\mathrm{c}}$ was calculated based on the bond length for the longest possible chain between two cross-links. After consideration of the sPEG core (tripentaerythritol), the vinylsulfone groups, and the peptide sequence for sPEG-Q and sPEG-K, a $c_{\mathrm{c}}$ of $0.025 \mathrm{w} / \mathrm{v} \%$ was obtained. In reality, gels can be formed for concentrations as low as $1 \mathrm{w} / \mathrm{v} \%$. The discrepancy of those two theoretical values can be explained by both the measurement error from the DLS (e.g., internal interactions, shrinking) leading to an underestimation of $r_{\mathrm{H}}$ and the fact that, in the theoretical model, a full stretch of the molecules is used to calculate the bond length, which results in an overestimation of $r_{\mathrm{H}}$. As both of these approaches to determine $c_{\mathrm{c}}$ depend on $r_{\mathrm{H}}$, a third approach to estimate $c_{\mathrm{c}}$ was performed based on the specific viscosity of the precursor solution at different concentrations inside the solvent. ${ }^{67}$ When

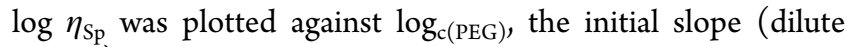
regime) changes in the regime of the overlap concentration. The critical concentration can be assigned to the intersection of the two lines representing both regimes, which is $4.27 \mathrm{w} / \mathrm{v} \%$ for the sPEG system presented here (Figure S3b). This value matches the sudden increase in stiffness observed between 2.5 and $5 \mathrm{w} / \mathrm{v} \%$ and is therefore the most reliable approach to determine the $c_{\mathrm{c}}$ in our system. This means that $(1-2.5) \mathrm{w} / \mathrm{v} \%$
sPEG gels are most likely made below the $\mathcal{c}_{\mathcal{c}}$, resulting in heterogeneous internal structures and pores. However, analysis of the internal gel structure via field emission scanning electron microscopy (FE-SEM) still shows a homogeneous and continuous network throughout the gel, even in the case of extremely soft and liquid-like $1 \mathrm{w} / \mathrm{v} \%$ sPEG hydrogels, which may be due to artifacts inherent to the FE-SEM technology (Figure S4).

3.3. Influence of FNIII9*-10/12-14 on Fibroblast Growth. In order to render our synthetic sPEG hydrogel biofunctional, a previously designed fibronectin fragment, FNIII9*-10/12-14, was produced and coupled into the network. The fragment has been reported to possess signaling synergy via binding domains for both cell integrins and growth factors. ${ }^{8}$ It was cloned and engineered with a transglutaminase substrate NQEQVSPL at the $\mathrm{N}$-terminus to bind to the free amines on the sPEG-K in the presence of FXIIIa and produced in E. coli. Successful production of the fragment was confirmed by sodium dodecyl sulfate polyacrylamide gel electrophoresis SDS-page (Figure S5). To induce cell spreading and proliferation inside the sPEG-based hydrogels, the hydrogel backbone was modified with different FNIII9*-10/12-14 concentrations $(0.1-5 \mu \mathrm{M})$ and compared to the commonly used short cell-adhesive peptide RGD ( $H$ NQEQVSPLRGDSPG- $\left.\mathrm{NH}_{2}\right)(5-100 \mu \mathrm{M})$ and full-length fibronectin $(1 \mu \mathrm{M})$. For all conditions, a low cell density of 400 fibroblasts $/ \mu \mathrm{L}$ was directly mixed within the hydrogel precursor solution $(2.5 \mathrm{w} / \mathrm{v} \% \mathrm{sPEG})$ to avoid immediate cell- 

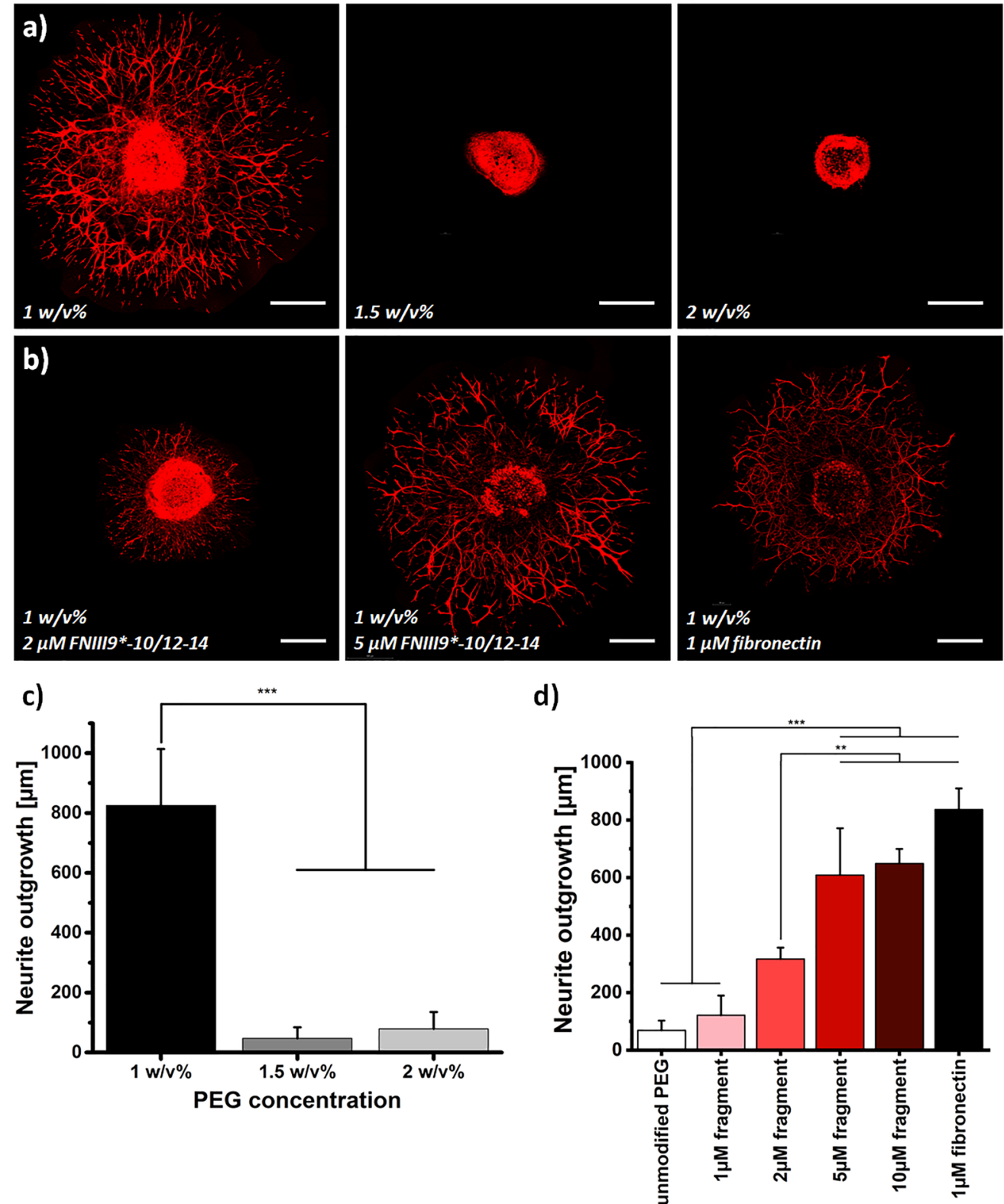

Figure 4. (a) Neurite outgrowth from a DRG in sPEG gels containing $5 \mu \mathrm{M}$ FNIII9*-10/12-14 for different polymer concentrations (1 to 1.5 to 2 $\mathrm{w} / \mathrm{v} \% \mathrm{sPEG}$, from left to right). (b) Variable concentrations of biomolecules: 2 and $5 \mu \mathrm{M}$ FNIII ${ }^{*}-10 / 12-14$ and $1 \mu \mathrm{M}$ fibronectin, from left to right. (c) Neurite outgrowth is significantly increased in $1 \mathrm{w} / \mathrm{v} \%$ hydrogels compared to 1.5 and $2 \mathrm{w} / \mathrm{v} \%$ sPEG. (d) Neurite outgrowth enhances with increasing FNIII9*-10/12-14 concentration with 5 and $10 \mu \mathrm{M}$ fragment being comparable to $1 \mu \mathrm{M}$ fibronectin. Scale bar is $500 \mu \mathrm{m}$. Data presented as average + s.d. and statistical significance performed using one-way ANOVA with Bonferroni comparison $\left(*^{*} p<0.05 ; * * p<0.01\right.$; $* * * p$ $<0.001)$.

cell contact and investigate the cell-material interaction. After 6 days, the fibroblast proliferation demonstrated enhanced growth in the case of hydrogels equipped with the fibronectin fragment. Fibroblast growth is already significantly increased for $0.5 \mu \mathrm{M}$ FNIII9*-10/12-14 compared to $5 \mu \mathrm{M}$ RGD, with even higher levels of proliferation for 2 and $5 \mu \mathrm{M}$ FNIII9*-10/ 12-14, respectively (Figure 2a). Furthermore, increasing the RGD concentration from 30 to $100 \mu \mathrm{M}$ did not significantly enhance cell proliferation, while 2 and $5 \mu \mathrm{M}$ FNIII9*-10/1214 led to similar cell growth compared to full-length fibronectin. After optimizing the concentration of FNIII9*$10 / 12-14$, the effect of the gel stiffness $\left(G^{\prime} \sim 10-3800 \mathrm{~Pa}\right.$ for $1-5 \mathrm{w} / \mathrm{v} \% \mathrm{sPEG}$, respectively) was analyzed for $2 \mu \mathrm{M}$ fragment, $1 \mu \mathrm{M}$ full-length fibronectin, and unmodified (blank) hydrogels (Figure 2b). In accordance with previous reports, cell proliferation increased for softer hydrogels, ${ }^{19,68-70}$ even for unmodified hydrogels, to which cells are less likely to attach. This suggests that cells can rapidly create sufficient space in the hydrogel by degrading the sparse network and produce their own ECM as a rescue mechanism to further support adhesion and subsequent proliferation. However, observations of cell morphology clearly showed that the reduced stiffness was not sufficient to support cell spreading when no biofunctional domains were added (Figure 2c). In the case of full-length fibronectin, a higher cell proliferation was observed compared to unmodified gels for all sPEG concentrations, except for $5 \mathrm{w} / \mathrm{v} \%$, demonstrating that the stiffest gel did not support 3D cell growth. For hydrogels, 
modified with FNIII9*-10/12-14, cell growth was improved over unmodified gels when the storage modulus was in the range of $10-100 \mathrm{~Pa}$. The softest hydrogel with FNIII9*-10/ 12-14 resulted in even higher levels of proliferation compared to full-length fibronectin (Figure 2b). Due to its smaller size $(51 \mathrm{kDa})$, compared to fibronectin $(\sim 220 \mathrm{kDa})$, the ECM fragment can easily be incorporated into the hydrogel at higher concentrations without significantly affecting the mechanical properties of the hydrogel (Figure S2d). In addition to cell division, cell spreading improved for softer gels with larger mesh sizes (Figure 2c), confirming that cells in a 3D environment need sufficient space to adhere to biomolecules and spread. However, based on the FE-SEM images, the mesh size of the ultrasoft $1 \mathrm{w} / \mathrm{v} \%$ sPEG gel was still estimated to be in the range of $0.25-1 \mu \mathrm{m}^{2}$, which is below the cells' deformability. ${ }^{71}$ Therefore, it remains crucial that the covalently cross-linked network can degrade to create more space for cell spreading, migration, and proliferation.

3.4. Fibronectin Fragments to Support Nerve Growth. To induce nerve growth, the effect of FNIII9*-10/ 12-14 was initially tested on 2D sPEG hydrogels using a high throughput robotic spotter technique adapted for this study (Figure 3a). ${ }^{72}$ An 8-arm sPEG-VS was cross-linked with a 4arm sPEG-SH via Michael-type addition and modified with the $\mathrm{K}$ peptide via a free cysteine to prepare a flat, thin hydrogel film (length, $75 \mathrm{~mm}$; width, $25 \mathrm{~mm}$; height, $170 \mu \mathrm{m}$ ). The fragments were then bound to the gel in an array of spots with a diameter of $450 \mu \mathrm{m}$ using activated FXIIIa in a scrambled manner. Besides the combinatorial fragment, the individual parts were tested to investigate the synergistic function of FNIII9*-10/12-14. The FN-fragments, FNIII9-10 (21 kDa), Leu1408Pro modified FNIII9*-10 (21 kDa), FNIII12-14 (31 $\mathrm{kDa})$, FNIII9-10/12-14 (51 kDa), and Leu1408Pro modified FNIII9*-10/12-14 $(51 \mathrm{kDa})$ were separately produced and coupled at a concentration of $1 \mathrm{nM}$, while full-length fibronectin was applied as a positive control at a concentration of $0.2 \mathrm{nM}$ due to its higher MW. To visualize the spotted fragment, FNIII9-10 was fluorescently labeled, revealing a homogeneous distribution inside the spot (Figure $3 \mathrm{~b}$ ). Dissociated cells from chick embryonic dorsal root ganglia (DRGs) were cultured on top of the gel for 4 days containing this library of FN-fragments in combination with four different media conditions (no growth factors or $2 \mathrm{ng} / \mathrm{mL}$ of the neurotrophic factor BDNF alone, or in combination with blocking antibodies against $\alpha_{5} \beta_{1}$ or $\alpha_{\mathrm{v}} \beta_{3}$ to assess the role of integrin binding). Brain derived neurotrophic factor (BDNF) has been shown to bind to FNIII12-14 in a previous report ${ }^{47}$ and is known to support DRG extension. ${ }^{73}$ Alternatively, NT-3 could have been used. Neurons were fixed and immune stained, after which a random selection of spots per protein condition was selected to quantify neurite extension with NeuronJ, an ImageJ plugin (Figure 3c). Nerve cells only attached and extended into spots modified with a cell adhesive protein. A synergistic effect of FNIII9*-10 and FNIII12-14 was observed, which has already been reported for bone tissue healing. ${ }^{8}$ The combinatorial fragment FNIII9*-10/12-14, containing both the cell adhesive and the growth factor domain in the same protein fragment, promoted nerve growth to a greater extent compared to any of the other fragments containing the individual domains (Figure $3 \mathrm{~d}$ ). In addition, it was confirmed that the Leu1408Pro modified FNIII9*-10/1214 significantly enhanced cell attachment compared to the nonmutated version. Interestingly, FNIII9*-10/12-14 also led to much more neurite extension compared to full-length fibronectin, which may be explained by the 5-fold lower concentration of fibronectin added to the spots of the sPEG film. If there was no protein spotted on the gel, only a low amount of neurite growth was observed if BDNF was added to the sample. To further prove the functional effect of FNIII9*10/12-14, antibodies against $\alpha_{5} \beta_{1}$ or $\alpha_{\mathrm{v}} \beta_{3}$ were added to block these integrins present on the cells, or BDNF was excluded from the media. In all cases, the positive effect on neurite extension was significantly reduced. In the case of full-length fibronectin, the changes in media composition did not affect nerve growth, indicating that other integrin binding domains present in fibronectin still support neurite extension. The results here demonstrate that the integrins $\alpha_{5} \beta_{1}$ and $\alpha_{\mathrm{v}} \beta_{3}$ play an important role in inducing neurite extension, directly or via promoting adhesion of supporting cells, such as Schwann cells, fibroblasts, etc., which were present in the DRG. Furthermore, the addition of anti- $\alpha_{\mathrm{V}}$ antibodies, reduced nerve growth more strongly compared to anti- $\alpha_{5}$ antibodies, which is in agreement with previous reports demonstrating a larger reduction in nerve growth after blocking the vitronectin receptor $\alpha_{v} \beta_{3}$, compared to inhibiting integrin $\alpha_{5} \beta_{1}{ }^{74}$ With the use of the robotic spotter, it was shown for the first time that FNIII9*-10/12-14 is a powerful biomolecule to support nerve regeneration. Therefore, this fragment was selected for the continuation of this study to modify sPEG-based hydrogels and investigate nerve growth in a $3 \mathrm{D}$ environment.

3.5. 3D Neurite Outgrowth Inside Tailored sPEG Hydrogels. To investigate the neurite outgrowth of primary nerve cells inside 3D hydrogels, whole DRGs were embedded within the precursor solution before cross-linking. ${ }^{50,75}$ First, to determine the optimal stiffness for nerve growth, different sPEG concentrations ranging from 1 to $2 \mathrm{w} / \mathrm{v} \%$ were investigated (Figure 4a). A fixed concentration of $5 \mu \mathrm{M}$ FNIII9*-10/12-14 was coupled to the gel, based on the results of the $3 \mathrm{D}$ experiment with fibroblasts. After optimizing the sPEG concentration, different concentrations of FNIII9*-10/ 12-14 were screened, varying from 1 to $10 \mu \mathrm{M}$ (Figure $4 \mathrm{~b}$, Figure $S 6 \mathrm{a}-\mathrm{c}$ ).

DRG outgrowth was quantified via image-based analysis of $\beta$ III tubulin immunostaining, using MatLab and Image J as previously described. ${ }^{58}$ In brief, after cutting out the explant, the images were rendered binary using Otsu's method and a MatLab code determined the number of nonzero valid image pixels dependent of the radial distance to the edge of the explant (Figure S6d-f). The density of samples was compared by determining the distance from the periphery of the DRG, at which the maximum signal dropped by half, which is here defined as "neurite outgrowth" (Figure S6g). Whereas no appreciable neurite outgrowth was observed for both 2 and 1.5 $\mathrm{w} / \mathrm{v} \%$ sPEG, a significant increase of neurite extension is observed for $1 \mathrm{w} / \mathrm{v} \%$ sPEG gels with a storage modulus of 10 $\mathrm{Pa}$ (Figure 4c). In addition, no swelling is observed for $1 \mathrm{w} / \mathrm{v} \%$ PEG gels, which avoids creating detrimental pressure to sensitive tissues like the spinal cord. The lack of swelling at this minimum concentration, at which gels can be formed, is likely due to the fact that the gel has no more capacity to take up more liquid. Interestingly, a storage modulus of $10 \mathrm{~Pa}$ is lower than the optimal stiffness for neurite growth reported for other hydrogel systems. For instance, in the case of fibrous fibrin gels, a storage modulus of approximately $425 \mathrm{~Pa}^{59}$ results in efficient nerve growth, while in the case of silk hydrogels, the optimal Young's modulus ranges from 7 to $22 \mathrm{kPa}^{23}$ In a 

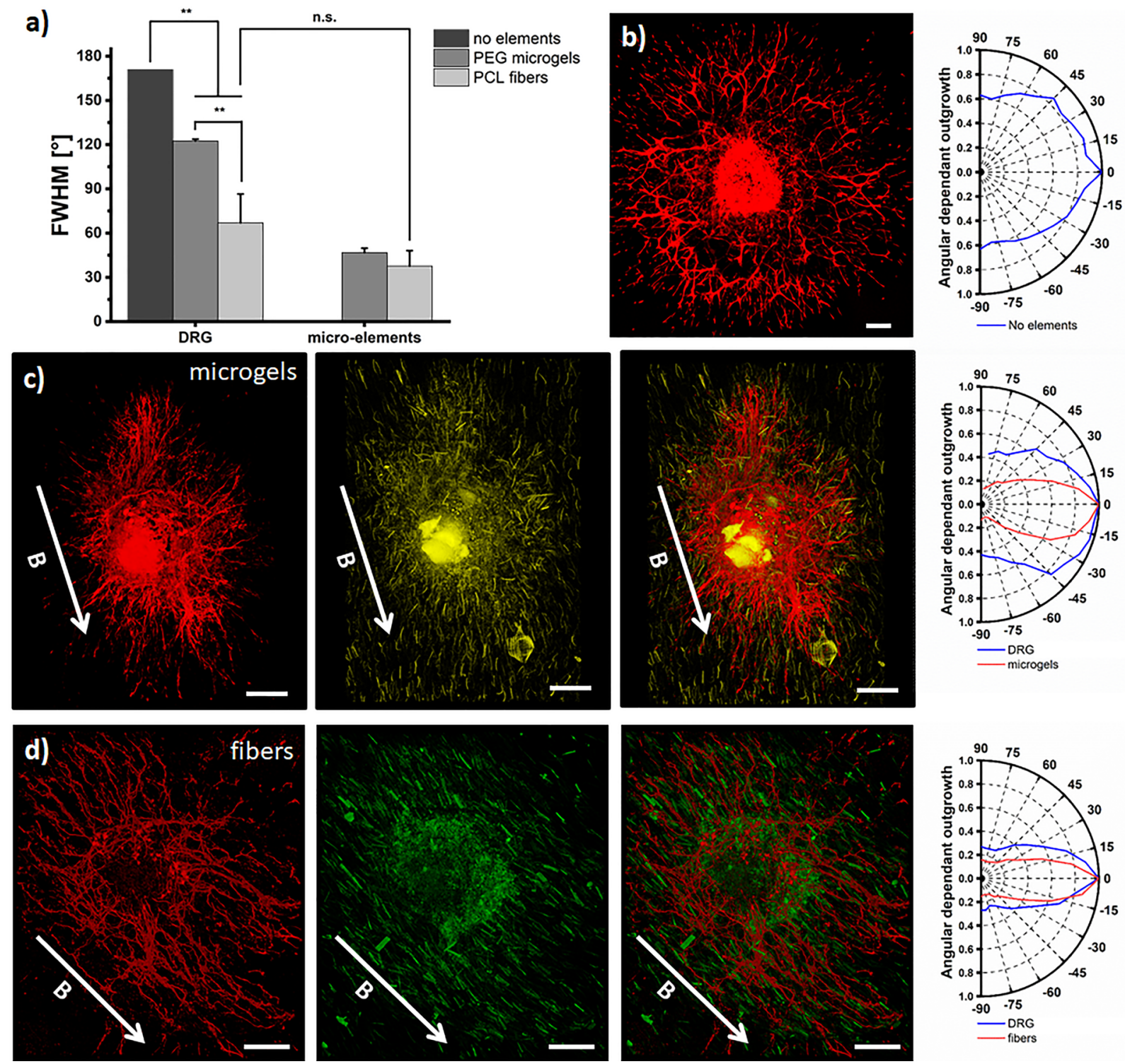

Figure 5. (a) Histogram comparing both DRG and microelement alignment $(n=3)$. (b) DRG in a $1 \mathrm{w} / \mathrm{v} \%$ PEG hydrogel without microelements and its associated angular dependent outgrowth. (c) Anisogel showing aligned DRG outgrowth and microgels, including an overlay of both and its corresponding angular dependent outgrowth (from left to right). (d) Anisogel showing aligned DRG outgrowth and fibers, including an overlay of both and its corresponding angular dependent outgrowth (from left to right). Scale bars are $200 \mu \mathrm{m}$. Data presented as average $+\mathrm{s}$.d. and statistical significance performed using one-way ANOVA with Bonferroni comparison $(* * p<0.01)$.

hyaluronic acid based hydrogel, a storage modulus of $\sim 100 \mathrm{~Pa}$ was shown to successfully support neurite outgrowth, ${ }^{76}$ while interestingly, even non-cross-linked PEG (600 Da) demonstrates axon regeneration through the material after spinal cord injury. ${ }^{22}$ This emphasizes the importance of the degradation rate, internal structure, and viscoelasticity as well.

In the case of different FNIII9*-10/12-14 concentrations, neurite outgrowth was enhanced with an increasing amount of FN-fragment, whereas no growth was observed inside unmodified hydrogels (Figure 4d). A minimal threshold of biofunctionality was seen, as concentrations above $2 \mu \mathrm{M}$ FNIII9*-10/12-14 were necessary to obtain efficient radial nerve growth, with enhanced growth in the case of 5 and 10 $\mu \mathrm{M}$ FNIII9*-10/12-14, as well as $1 \mu \mathrm{M}$ full-length FN (Figure $4 \mathrm{~b})$. Based on these results, $5 \mu \mathrm{M}$ was selected as the optimal FNIII9*-10/12-14 concentration to support nerve growth in 3D sPEG hydrogels since $10 \mu \mathrm{M}$ of the fragment did not further increase neurite outgrowth significantly. The results of this report thus demonstrate that the presence of the engineered FNIII9*-10/12-14 inside synthetic sPEG hydrogels is a powerful method to render the matrix cell adhesive, comparable to or even better than large ECM molecules, and is superior compared to small RGD peptides.

3.6. Directed Nerve Growth in sPEG Anisogel. To induce linear guidance of nerve growth in our injectable hydrogels, small, anisometric micron-scale $(\mu$ - $)$ elements were loaded with superparamagnetic iron oxide nanoparticles (SPIONs) and incorporated inside the sPEG precursor solution to create an Anisogel. Our group previously reported the concept of the Anisogel, which contains these magnetoresponsive, rod-shaped $\mu$-elements that orient in the presence of an external magnetic field, after which a surrounding gel cross-links to fix the aligned elements. The Anisogel has been demonstrated to direct growth of fibroblasts and functional 
nerves inside fibrin-based Anisogels with a minimal amount of guiding elements $\left(1 \mathrm{v} / \mathrm{v} \%\right.$ of the entire gel). ${ }^{57,59}$ However, as natural fibrin gels bear a risk of pathogen transmission and degrade rapidly in vivo within a few weeks, ${ }^{60}$ the Anisogel concept is here translated to the sPEG-hydrogel combined with FNIII9*-10/12-14. The main advantage of using synthetic hydrogels for clinical use is their easier control of mechanical and physical properties over time (e.g., gelation time, degradation), and specific biofunctionalization, which is demonstrated in this report. To achieve successful nerve repair, it is crucial that the kinetics of scaffold degradation and cell infiltration match, as the cells will produce their own natural ECM to replace the synthetic matrix. In addition, we previously demonstrated that the ECM produced by aligned cells inside an Anisogel is also aligned, which provides a positive feedback cycle, creating natural guidance as the Anisogel degrades. ${ }^{58}$ Although in vitro, degradation of fibrin can be inhibited by the addition of aprotinin in the media, this remains a limitation for the use of fibrin as a long-term supporting matrix in vivo. ${ }^{77}$ Two types of guiding elements with similar dimensions are compared: rod-shaped PEG-based microgels $\left(5 \times 5 \times 50 \mu \mathrm{m}^{3}\right)$ and short polycaprolactone (PCL) fibers (diameter of $\sim 5 \mu \mathrm{m}$ and length of $\sim 50 \mu \mathrm{m}$ ). Both are incorporated at a concentration of $1 \mathrm{v} / \mathrm{v} \%$ and aligned in the presence of a low external magnetic field $(100 \mathrm{mT})$. Their position is fixed during gelation of the surrounding sPEG precursor solution, after which the magnetic field can be removed. To successfully align the $\mu$-elements, the gelation kinetics of the sPEG hydrogels were optimized by altering the FXIIIa concentration. In the case of rod-shaped microgels, which consist of $20 \mathrm{w} / \mathrm{v} \%$ PEG-based polymer and orient within $35 \mathrm{~s},{ }^{57}$ doubling the FXIIIa concentration from 10 to 20 $\mathrm{U} / \mathrm{mL}$ is sufficient to avoid settling of the microgels due to gravity and obtain an anisotropic hybrid hydrogel comparable to the fibrin-based Anisogel (Figure S7). In the case of short fibers, which are heavier than the microgels as they consist of $100 \%$ PCL polymer, well distributed, oriented fibers were obtained inside the gel when increasing the enzyme concentration up to $100 \mathrm{U} / \mathrm{mL}$. After injection, both microgels and short fibers aligned efficiently with a full width at halfmaximum (FWHM) of $46^{\circ}$ and $37^{\circ}$, respectively (Figure 5ad). The slightly better alignment of the fibers may be due to the higher concentration of SPIONs or their difference in stiffness. In both cases, nerves extended in the direction of the aligned $\mu$-elements, compared to random growth in a sPEG gel without elements. In a PEG-based Anisogel containing fibers, the level of nerve alignment (FWHM: 67 $)$ was not significantly different from the level of fiber alignment. In contrast, nerves surrounded by the aligned microgels showed a reduced level of alignment (FWHM: $127^{\circ}$ ). This can most likely be explained by their difference in stiffness and celladhesiveness as the fibers consist of 100\% PCL and the microgels contain $20 \%$ bioinert sPEG. In future studies, the microgels will be varied in stiffness and coupled with cell adhesive peptides ${ }^{58}$ to investigate how this will affect the function of a fully synthetic Anisogel.

\section{CONCLUSIONS}

A fully synthetic PEG-based Anisogel was developed to induce aligned growth of nerve cells. The surrounding sPEG hydrogel cross-links enzymatically with activated factor XIII, similar to fibrin, and contains MMP sensitive domains to enable degradation on cell demand. The rheological properties of the sPEG hydrogel depend on both the polymer and enzyme concentration with storage moduli ranging from 10 to $3800 \mathrm{~Pa}$ and gelation times between 10 and $2 \mathrm{~min}$. The initially bioinert hydrogel is modified with a recombinant fibronectin fragment, FNIII9*-10/12-14, resulting in similar neurite outgrowth compared to full-length fibronectin and better than short RGD peptides. A first systematic study demonstrated optimal fibroblast spreading and proliferation in very soft $1 \mathrm{w} / \mathrm{v} \%$ sPEG hydrogels of only $10 \mathrm{~Pa}$. For nerve cells, the initial stiffness is even more critical. At stiffnesses equal to or above $100 \mathrm{~Pa}$, no neuronal outgrowth could be observed. The recombinant FNIII9*-10/12-14 fragment promotes nerve growth with a synergistic effect between the FNIII9*-10 and FNIII12-14 domains, demonstrating the importance of both the integrin and growth factor binding domain. In 3D sPEG hydrogels, a FNIII9*-10/12-14 concentration of $5 \mu \mathrm{M}$ is optimal to promote neurite extension, with no significant difference from full-length fibronectin. Combining the $10 \mathrm{~Pa}$ soft synthetic hydrogel with $5 \mu \mathrm{M}$ of the recombinant fibronectin fragment and $1 \mathrm{v} / \mathrm{v} \%$ of homogeneously distributed magnetically aligned $\mu$-elements $\left(50 \times 50 \times 5 \mu \mathrm{m}^{3}\right)$ demonstrated for the first time that a fully synthetic, injectable Anisogel is able to induce nerve growth in an oriented manner parallel to the elements. This concept is an important step toward clinical translation of a regenerative treatment of hierarchically structured tissue.

\section{ASSOCIATED CONTENT}

\section{Supporting Information}

The Supporting Information is available free of charge on the ACS Publications website at DOI: 10.1021/acs.biomac.9b00891.

Materials and methods, ${ }^{1} \mathrm{H}$ NMR analysis of peptidesPEG coupling, additional rheological results, DLS measurement of sPEG-Q FE-SEM images of a $1 \mathrm{w} / \mathrm{v}$ $\%$ sPEG-gel, SDS-PAGE of protein purification process, complementary confocal images and analysis method of DRG outgrowth, microgel comparison in fibrin and sPEG (PDF)

Video file of rotating SI $8 \mathrm{a}, \mathrm{b}$ (AVI)

Video file of rotating SI 8c,d (AVI)

\section{AUTHOR INFORMATION}

\section{Corresponding Author}

*E-mail: delaporte@dwi.rwth-aachen.de. ORCID

Jonas C. Rose: 0000-0003-3245-5061

Abdolrahman Omidinia Anarkoli: 0000-0001-9680-8431

Tamás Haraszti: 0000-0002-7095-4358

David B. Gehlen: 0000-0001-5792-4528

Jeffrey A. Hubbell: 0000-0003-0276-5456

Laura De Laporte: 0000-0002-9438-0977

Notes

The authors declare no competing financial interest.

\section{ACKNOWLEDGMENTS}

We acknowledge funding from the European Research Council (ERC) under the European Union's Horizon 2020 research and innovation program (ANISOGEL, grant agreement no. 637853), the Deutsche Forschungsgemeinschaft (DFG) within the SFB 985 "Functional Microgels and Microgel Systems", 
and the European Commission (EUSMI, 731019). This work was performed in part at the Center for Chemical Polymer Technology CPT, which was supported by the EU and the federal state of North Rhine-Westphalia (grant EFRE 3000 883 02). We furthermore thank S. Moli for experimental assistance. Moreover, cDNA of FNIII9*-10/12-14 in the expression vector pGEX-6P-1 was kindly provided from the laboratory of Prof. Jeffrey Hubbell lab at the University of Chicago.

\section{REFERENCES}

(1) Annabi, N.; Tamayol, A.; Uquillas, J. A.; Akbari, M.; Bertassoni, L. E.; Cha, C.; Camci-Unal, G.; Dokmeci, M. R.; Peppas, N. A.; Khademhosseini, A. 25th anniversary article: Rational design and applications of hydrogels in regenerative medicine. Adv. Mater. 2014, $26(1), 85-123$.

(2) Gomes, M. E.; Rodrigues, M. T.; Domingues, R. M. A.; Reis, R. L. Tissue Engineering and Regenerative Medicine: New Trends and Directions-A Year in Review. Tissue Eng., Part B 2017, 23 (3), 211224.

(3) Yang, J. A.; Yeom, J.; Hwang, B. W.; Hoffman, A. S.; Hahn, S. K. In situ-forming injectable hydrogels for regenerative medicine. Prog. Polym. Sci. 2014, 39 (12), 1973-1986.

(4) Zhang, Y. S.; Khademhosseini, A. Advances in engineering hydrogels. Science 2017, 356 (6337), eaaf3627.

(5) Rice, J. J.; Martino, M. M.; De Laporte, L.; Tortelli, F.; Briquez, P. S.; Hubbell, J. A. Engineering the regenerative microenvironment with biomaterials. Adv. Healthcare Mater. 2013, 2 (1), 57-71.

(6) Hern, D. L.; Hubbell, J. A. Incorporation of adhesion peptides into nonadhesive hydrogels useful for tissue resurfacing. J. Biomed. Mater. Res. 1998, 39 (2), 266-76.

(7) Lutolf, M. P.; Raeber, G. P.; Zisch, A. H.; Tirelli, N.; Hubbell, J. A. Cell-responsive synthetic hydrogels. Adv. Mater. 2003, 15 (11), 888-892.

(8) Martino, M. M.; Tortelli, F.; Mochizuki, M.; Traub, S.; BenDavid, D.; Kuhn, G. A.; Muller, R.; Livne, E.; Eming, S. A.; Hubbell, J. A. Engineering the growth factor microenvironment with fibronectin domains to promote wound and bone tissue healing. Sci. Transl. Med. 2011, 3 (100), 100ra89.

(9) Lohmann, N.; Schirmer, L.; Atallah, P.; Wandel, E.; Ferrer, R. A.; Werner, C.; Simon, J. C.; Franz, S.; Freudenberg, U. Glycosaminoglycan-based hydrogels capture inflammatory chemokines and rescue defective wound healing in mice. Sci. Transl. Med. 2017, 9 (386), eaai9044.

(10) Browning, M. B.; Cereceres, S. N.; Luong, P. T.; CosgriffHernandez, E. M. Determination of the in vivo degradation mechanism of PEGDA hydrogels. J. Biomed. Mater. Res., Part A 2014, 102 (12), 4244-51.

(11) Caiazzo, M.; Okawa, Y.; Ranga, A.; Piersigilli, A.; Tabata, Y.; Lutolf, M. P. Defined three-dimensional microenvironments boost induction of pluripotency. Nat. Mater. 2016, 15 (3), 344-52.

(12) Discher, D. E.; Janmey, P.; Wang, Y. L. Tissue cells feel and respond to the stiffness of their substrate. Science 2005, 310 (5751), 1139-43.

(13) Leach, J. B.; Brown, X. Q.; Jacot, J. G.; Dimilla, P. A.; Wong, J. Y. Neurite outgrowth and branching of PC12 cells on very soft substrates sharply decreases below a threshold of substrate rigidity. $J$. Neural Eng. 2007, 4 (2), 26-34.

(14) Beningo, K. A.; Dembo, M.; Wang, Y. L. Responses of fibroblasts to anchorage of dorsal extracellular matrix receptors. Proc. Natl. Acad. Sci. U. S. A. 2004, 101 (52), 18024-9.

(15) Cukierman, E.; Pankov, R.; Stevens, D. R.; Yamada, K. M. Taking cell-matrix adhesions to the third dimension. Science 2001, 294 (5547), 1708-12.

(16) Pelham, R. J. Jr.; Wang, Y. Cell locomotion and focal adhesions are regulated by substrate flexibility. Proc. Natl. Acad. Sci. U. S. A. 1997, 94 (25), 13661-5.
(17) Chaudhuri, O.; Gu, L.; Darnell, M.; Klumpers, D.; Bencherif, S. A.; Weaver, J. C.; Huebsch, N.; Mooney, D. J. Substrate stress relaxation regulates cell spreading. Nat. Commun. 2015, 6, 6364.

(18) Yeung, T.; Georges, P. C.; Flanagan, L. A.; Marg, B.; Ortiz, M.; Funaki, M.; Zahir, N.; Ming, W.; Weaver, V.; Janmey, P. A. Effects of substrate stiffness on cell morphology, cytoskeletal structure, and adhesion. Cell Motil. Cytoskeleton 2005, 60 (1), 24-34.

(19) Ehrbar, M.; Sala, A.; Lienemann, P.; Ranga, A.; Mosiewicz, K.; Bittermann, A.; Rizzi, S. C.; Weber, F. E.; Lutolf, M. P. Elucidating the role of matrix stiffness in 3D cell migration and remodeling. Biophys. J. 2011, 100 (2), 284-93.

(20) Gjorevski, N.; Sachs, N.; Manfrin, A.; Giger, S.; Bragina, M. E.; Ordonez-Moran, P.; Clevers, H.; Lutolf, M. P. Designer matrices for intestinal stem cell and organoid culture. Nature 2016, 539 (7630), $560-564$.

(21) Koser, D. E.; Thompson, A. J.; Foster, S. K.; Dwivedy, A.; Pillai, E. K.; Sheridan, G. K.; Svoboda, H.; Viana, M.; Costa, L. D.; Guck, J.; Holt, C. E.; Franze, K. Mechanosensing is critical for axon growth in the developing brain. Nat. Neurosci. 2016, 19 (12), 1592-1598.

(22) Estrada, V.; Brazda, N.; Schmitz, C.; Heller, S.; Blazyca, H.; Martini, R.; Muller, H. W. Long-lasting significant functional improvement in chronic severe spinal cord injury following scar resection and polyethylene glycol implantation. Neurobiol. Dis. 2014, 67, 165-79.

(23) Hopkins, A. M.; De Laporte, L.; Tortelli, F.; Spedden, E.; Staii, C.; Atherton, T. J.; Hubbell, J. A.; Kaplan, D. L. Silk Hydrogels as Soft Substrates for Neural Tissue Engineering. Adv. Funct. Mater. 2013, 23 (41), 5140-5149.

(24) Georges, P. C.; Miller, W. J.; Meaney, D. F.; Sawyer, E. S.; Janmey, P. A. Matrices with compliance comparable to that of brain tissue select neuronal over glial growth in mixed cortical cultures. Biophys. J. 2006, 90 (8), 3012-8.

(25) Jiang, F. X.; Yurke, B.; Firestein, B. L.; Langrana, N. A. Neurite outgrowth on a DNA crosslinked hydrogel with tunable stiffnesses. Ann. Biomed. Eng. 2008, 36 (9), 1565-79.

(26) Freudenberg, U.; Hermann, A.; Welzel, P. B.; Stirl, K.; Schwarz, S. C.; Grimmer, M.; Zieris, A.; Panyanuwat, W.; Zschoche, S.; Meinhold, D.; Storch, A.; Werner, C. A star-PEG-heparin hydrogel platform to aid cell replacement therapies for neurodegenerative diseases. Biomaterials 2009, 30 (28), 5049-60.

(27) Koser, D. E.; Moeendarbary, E.; Hanne, J.; Kuerten, S.; Franze, $\mathrm{K}$. CNS cell distribution and axon orientation determine local spinal cord mechanical properties. Biophys. J. 2015, 108 (9), 2137-47.

(28) Wright, N. M.; Park, J.; Tew, J. M.; Kim, K. D.; Shaffrey, M. E.; Cheng, J.; Choudhri, H.; Krishnaney, A. A.; Graham, R. S.; Mendel, E.; Simmons, N. Spinal sealant system provides better intraoperative watertight closure than standard of care during spinal surgery: a prospective, multicenter, randomized controlled study. Spine (Philadelphia) 2015, 40 (8), 505-13.

(29) Allen, M. S.; Wood, D. E.; Hawkinson, R. W.; Harpole, D. H.; McKenna, R. J.; Walsh, G. L.; Vallieres, E.; Miller, D. L.; Nichols, F. C., 3rd; Smythe, W. R.; Davis, R. D. Prospective randomized study evaluating a biodegradable polymeric sealant for sealing intraoperative air leaks that occur during pulmonary resection. Ann. Thorac Surg 2004, 77 (5), 1792-801.

(30) van Gysen, K.; Kneebone, A.; Alfieri, F.; Guo, L.; Eade, T. Feasibility of and rectal dosimetry improvement with the use of SpaceOAR(R) hydrogel for dose-escalated prostate cancer radiotherapy. J. Med. Imaging Radiat Oncol 2014, 58 (4), 511-6.

(31) Joly, P.; Duda, G. N.; Schone, M.; Welzel, P. B.; Freudenberg, U.; Werner, C.; Petersen, A. Geometry-driven cell organization determines tissue growths in scaffold pores: consequences for fibronectin organization. PLoS One 2013, 8 (9), No. e73545.

(32) Kim, J.; Kong, Y. P.; Niedzielski, S. M.; Singh, R. K.; Putnam, A. J.; Shikanov, A. Characterization of the crosslinking kinetics of multiarm poly(ethylene glycol) hydrogels formed via Michael-type addition. Soft Matter 2016, 12 (7), 2076-85. 
(33) Lutolf, M. P.; Tirelli, N.; Cerritelli, S.; Cavalli, L.; Hubbell, J. A. Systematic modulation of Michael-type reactivity of thiols through the use of charged amino acids. Bioconjugate Chem. 2001, 12 (6), 1051-6. (34) Yamaoka, T.; Tabata, Y.; Ikada, Y. Distribution and tissue uptake of poly(ethylene glycol) with different molecular weights after intravenous administration to mice. J. Pharm. Sci. 1994, 83 (4), 6016.

(35) Ehrbar, M.; Rizzi, S. C.; Schoenmakers, R. G.; Miguel, B. S.; Hubbell, J. A.; Weber, F. E.; Lutolf, M. P. Biomolecular hydrogels formed and degraded via site-specific enzymatic reactions. Biomacromolecules 2007, 8 (10), 3000-7.

(36) Lampe, K. J.; Bjugstad, K. B.; Mahoney, M. J. Impact of degradable macromer content in a poly(ethylene glycol) hydrogel on neural cell metabolic activity, redox state, proliferation, and differentiation. Tissue Eng., Part A 2010, 16 (6), 1857-66.

(37) Ehrbar, M.; Rizzi, S. C.; Hlushchuk, R.; Djonov, V.; Zisch, A. H.; Hubbell, J. A.; Weber, F. E.; Lutolf, M. P. Enzymatic formation of modular cell-instructive fibrin analogs for tissue engineering. Biomaterials 2007, 28 (26), 3856-66.

(38) Pittman, R. N.; Buettner, H. M. Degradation of extracellular matrix by neuronal proteases. Dev. Neurosci. 1989, 11 (4-5), 361-75.

(39) Patterson, J.; Hubbell, J. A. Enhanced proteolytic degradation of molecularly engineered PEG hydrogels in response to MMP-1 and MMP-2. Biomaterials 2010, 31 (30), 7836-45.

(40) Rangappa, N.; Romero, A.; Nelson, K. D.; Eberhart, R. C.; Smith, G. M. Laminin-coated poly(L-lactide) filaments induce robust neurite growth while providing directional orientation. J. Biomed. Mater. Res. 2000, 51 (4), 625-34.

(41) Baron-Van Evercooren, A.; Kleinman, H. K.; Ohno, S.; Marangos, P.; Schwartz, J. P.; Dubois-Dalcq, M. E. Nerve growth factor, laminin, and fibronectin promote neurite growth in human fetal sensory ganglia cultures. J. Neurosci. Res. 1982, 8 (2-3), 179-93.

(42) Flanagan, L. A.; Ju, Y. E.; Marg, B.; Osterfield, M.; Janmey, P. A. Neurite branching on deformable substrates. NeuroReport 2002, 13 (18), 2411-5.

(43) Balgude, A. P.; Yu, X.; Szymanski, A.; Bellamkonda, R. V. Agarose gel stiffness determines rate of DRG neurite extension in $3 \mathrm{D}$ cultures. Biomaterials 2001, 22 (10), 1077-84.

(44) Schense, J. C.; Bloch, J.; Aebischer, P.; Hubbell, J. A. Enzymatic incorporation of bioactive peptides into fibrin matrices enhances neurite extension. Nat. Biotechnol. 2000, 18 (4), 415-9.

(45) Gunn, J. W.; Turner, S. D.; Mann, B. K. Adhesive and mechanical properties of hydrogels influence neurite extension. J. Biomed. Mater. Res. 2005, 72 (1), 91-7.

(46) Martino, M. M.; Briquez, P. S.; Ranga, A.; Lutolf, M. P.; Hubbell, J. A. Heparin-binding domain of fibrin(ogen) binds growth factors and promotes tissue repair when incorporated within a synthetic matrix. Proc. Natl. Acad. Sci. U. S. A. 2013, 110 (12), 45638.

(47) Martino, M. M.; Hubbell, J. A. The 12th-14th type III repeats of fibronectin function as a highly promiscuous growth factor-binding domain. FASEB J. 2010, 24 (12), 4711-21.

(48) van der Walle, C. F.; Altroff, H.; Mardon, H. J. Novel mutant human fibronectin FIII9-10 domain pair with increased conformational stability and biological activity. Protein Eng., Des. Sel. 2002, 15 (12), 1021-4.

(49) Geller, H. M.; Fawcett, J. W. Building a bridge: engineering spinal cord repair. Exp. Neurol. 2002, 174 (2), 125-36.

(50) Macaya, D.; Spector, M. Injectable hydrogel materials for spinal cord regeneration: a review. Biomed. Mater. 2012, 7 (1), 012001.

(51) Pakulska, M. M.; Ballios, B. G.; Shoichet, M. S. Injectable hydrogels for central nervous system therapy. Biomed. Mater. 2012, 7 (2), 024101.

(52) Tseng, T. C.; Tao, L.; Hsieh, F. Y.; Wei, Y.; Chiu, I. M.; Hsu, S. H. An Injectable, Self-Healing Hydrogel to Repair the Central Nervous System. Adv. Mater. 2015, 27 (23), 3518-24.

(53) Berns, E. J.; Sur, S.; Pan, L.; Goldberger, J. E.; Suresh, S.; Zhang, S.; Kessler, J. A.; Stupp, S. I. Aligned neurite outgrowth and directed cell migration in self-assembled monodomain gels. Biomaterials 2014, 35 (1), 185-95.

(54) Ansorena, E.; De Berdt, P.; Ucakar, B.; Simon-Yarza, T.; Jacobs, D.; Schakman, O.; Jankovski, A.; Deumens, R.; Blanco-Prieto, M. J.; Preat, V.; des Rieux, A. Injectable alginate hydrogel loaded with GDNF promotes functional recovery in a hemisection model of spinal cord injury. Int. J. Pharm. 2013, 455 (1-2), 148-58.

(55) Kim, J.; Staunton, J. R.; Tanner, K. Independent Control of Topography for 3D Patterning of the ECM Microenvironment. Adv. Mater. 2016, 28 (1), 132-7.

(56) Antman-Passig, M.; Shefi, O. Remote Magnetic Orientation of 3D Collagen Hydrogels for Directed Neuronal Regeneration. Nano Lett. 2016, 16 (4), 2567-2573.

(57) Rose, J. C.; Camara-Torres, M.; Rahimi, K.; Kohler, J.; M?ller, M.; De Laporte, L. Nerve Cells Decide to Orient inside an Injectable Hydrogel with Minimal Structural Guidance. Nano Lett. 2017, 17 (6), $3782-3791$

(58) Rose, J. C.; Gehlen, D. B.; Haraszti, T.; Kohler, J.; Licht, C. J.; De Laporte, L. Biofunctionalized aligned microgels provide 3D cell guidance to mimic complex tissue matrices. Biomaterials 2018, 163, $128-141$.

(59) Omidinia-Anarkoli, A.; Boesveld, S.; Tuvshindorj, U.; Rose, J. C.; Haraszti, T.; De Laporte, L. An Injectable Hybrid Hydrogel with Oriented Short Fibers Induces Unidirectional Growth of Functional Nerve Cells. Small 2017, 13 (36), 1702207.

(60) Wolbank, S.; Pichler, V.; Ferguson, J. C.; Meinl, A.; van Griensven, M.; Goppelt, A.; Redl, H. Non-invasive in vivo tracking of fibrin degradation by fluorescence imaging. J. Tissue Eng. Regener. Med. 2015, 9 (8), 973-6.

(61) Omidinia-Anarkoli, A.; Rimal, R.; Chandorkar, Y.; Gehlen, D. B.; Rose, J. C.; Rahimi, K.; Haraszti, T.; De Laporte, L. SolventInduced Nanotopographies of Single Microfibers Regulate Cell Mechanotransduction. ACS Appl. Mater. Interfaces 2019, 11 (8), $7671-7685$.

(62) Zemel, A.; Rehfeldt, F.; Brown, A. E. X.; Discher, D. E.; Safran, S. A. Optimal matrix rigidity for stress-fibre polarization in stem cells. Nat. Phys. 2010, 6 (6), 468-473.

(63) Missirlis, D.; Haraszti, T.; Scheele, C. V. C.; Wiegand, T.; Diaz, C.; Neubauer, S.; Rechenmacher, F.; Kessler, H.; Spatz, J. P. Substrate engagement of integrins alpha(5)beta(1) and alpha(v)beta(3) is necessary, but not sufficient, for high directional persistence in migration on fibronectin. Sci. Rep. 2016, 6, 6.

(64) Lorand, L.; Graham, R. M. Transglutaminases: crosslinking enzymes with pleiotropic functions. Nat. Rev. Mol. Cell Biol. 2003, 4 (2), 140-56.

(65) Discher, D. E.; Mooney, D. J.; Zandstra, P. W. Growth factors, matrices, and forces combine and control stem cells. Science 2009, 324 (5935), 1673-7.

(66) Sakai, T.; Matsunaga, T.; Yamamoto, Y.; Ito, C.; Yoshida, R.; Suzuki, S.; Sasaki, N.; Shibayama, M.; Chung, U. I. Design and fabrication of a high-strength hydrogel with ideally homogeneous network structure from tetrahedron-like macromonomers. Macromolecules 2008, 41 (14), 5379-5384.

(67) Wehrman, M. D.; Leduc, A.; Callahan, H. E.; Mazzeo, M. S.; Schumm, M.; Schultz, K. M. Rheological Properties and Structure of Step- and Chain-Growth Gels Concentrated above the Overlap Concentration. AIChE J. 2018, 64 (8), 3168-3176.

(68) Wang, C.; Tong, X.; Yang, F. Bioengineered 3D brain tumor model to elucidate the effects of matrix stiffness on glioblastoma cell behavior using PEG-based hydrogels. Mol. Pharmaceutics 2014, 11 (7), 2115-25.

(69) Rao, S. S.; Dejesus, J.; Short, A. R.; Otero, J. J.; Sarkar, A.; Winter, J. O. Glioblastoma behaviors in three-dimensional collagenhyaluronan composite hydrogels. ACS Appl. Mater. Interfaces 2013, 5 (19), 9276-84.

(70) Liu, J.; Tan, Y.; Zhang, H.; Zhang, Y.; Xu, P.; Chen, J.; Poh, Y. C.; Tang, K.; Wang, N.; Huang, B. Soft fibrin gels promote selection and growth of tumorigenic cells. Nat. Mater. 2012, 11 (8), 734-41. 
(71) Wolf, K.; Te Lindert, M.; Krause, M.; Alexander, S.; Te Riet, J.; Willis, A. L.; Hoffman, R. M.; Figdor, C. G.; Weiss, S. J.; Friedl, P. Physical limits of cell migration: control by ECM space and nuclear deformation and tuning by proteolysis and traction force. J. Cell Biol. 2013, 201 (7), 1069-84.

(72) Gobaa, S.; Hoehnel, S.; Roccio, M.; Negro, A.; Kobel, S.; Lutolf, M. P. Artificial niche microarrays for probing single stem cell fate in high throughput. Nat. Methods 2011, 8 (11), 949-55.

(73) Huang, E. J.; Reichardt, L. F. Neurotrophins: roles in neuronal development and function. Annu. Rev. Neurosci. 2001, 24, 677-736.

(74) Felding-Habermann, B.; Cheresh, D. A. Vitronectin and its receptors. Curr. Opin. Cell Biol. 1993, 5 (5), 864-8.

(75) Assuncao-Silva, R. C.; Gomes, E. D.; Sousa, N.; Silva, N. A.; Salgado, A. J. Hydrogels and Cell Based Therapies in Spinal Cord Injury Regeneration. Stem Cells Int. 2015, 2015, 948040.

(76) Broguiere, N.; Isenmann, L.; Zenobi-Wong, M. Novel enzymatically cross-linked hyaluronan hydrogels support the formation of 3D neuronal networks. Biomaterials 2016, 99, 47-55.

(77) Lorentz, K. M.; Kontos, S.; Frey, P.; Hubbell, J. A. Engineered aprotinin for improved stability of fibrin biomaterials. Biomaterials 2011, 32 (2), 430-8. 